\title{
EMOTIONS EXPLICATION IN THE TEXT AND THE FILM TEXT: INTERSEMIOTIC TRANSLATION OF THE NOVEL PERFUME. THE STORY OF A MURDERER BY PATRICK SUSKIND
}

\author{
Ekaterina V. Nesmachnova \\ Volgograd State University, Volgograd, Russian Federation
}

\begin{abstract}
The results of the study, connected with the current interdisciplinary problem, which is the visualization of the culture, are described in the article. On the example of the novel by the German writer P. Suskind Perfume. The History of a Murderer (Patrick Süskind, Das Parfum. Die Geschichte eines Mörders) and the Germanlanguage version of the film directed by Tom Tykwer the possibilities of conveying the content of the verbal text in other semiotic systems are studied. The means of explication of emotions associated with the implementation of the concept of "smell," which presents the plot-forming function in the novel, is the object of the article.

With the use of the concept of "intersemiotic translation" in a communicative aspect, different ways of transforming the text of a literary work into a cinema text are identified through visual possibilities in the reproduction of the emotional space of the novel. It is established that in the process of creation of the film version of the novel (polysemiotic system), the techniques of the verbal text transformation are used, similar to the methods of translation within the boundaries of one (verbal) semiotic system: compression, permutation, manifested in the form of paraphrasing, and modulation as an adequate replacement and explanatory translation. It is shown that the means of expressing emotions, used for intersemiotic translation, are meaningfully adequate to the verbal means used in the literary work.

Key words: communicative action, visualization, verbal element of communication, non-verbal element of communication, transformation, film text, emotionality, P. Suskind.

Citation. Nesmachnova E.V. Emotions Explication in the Text and the Film Text: Intersemiotic Translation of the Novel Perfume. The Story of a Murderer by Patrick Suskind. Vestnik Volgogradskogo gosudarstvennogo universiteta. Seriya 2, Yazykoznanie [Science Journal of Volgograd State University. Linguistics], 2017, vol. 16, no. 3, pp. 214-220. (in Russian). DOI: https://doi.org/10.15688/jvolsu2.2017.3.22
\end{abstract}

\section{ЭКСПЛИКАЦИЯ ЭМОЦИЙ В ТЕКСТЕ И КИНОТЕКСТЕ: ИНТЕРСЕМИОТИЧЕСКИЙ ПЕРЕВОД РОМАНА П. ЗЮСКИНДА «ПАРФЮМЕР. ИСТОРИЯ ОДНОГО УБИЙЦЫ»}

\author{
Екатерина Владимировна Несмачнова

Аннотация. Исследование, результаты которого обобщены в статье, находится в русле актуальной междисциплинарной проблемы - визуализации культуры. На примере романа немецкого писателя П. Зюскинда «Парфюмер. История одного убийцы» (Patrick Süskind. Das Parfum. Die Geschichte eines Mörders) и немецкоязычной версии одноименного фильма режиссера Тома Тыквера (Tom Tykwer) изучаются возможности передачи содержания вербального текста в иных семиотических системах. Объектом исследования стали средства экспликации эмоций, связанные с реализацией концепта «запах», который выполняет в романе сюжетообразующую функцию. 
С использованием понятия «интерсемиотический перевод» в коммуникативном аспекте и с учетом визуальных возможностей в воспроизведении эмоционального пространства романа выявлены способы трансформации текста литературного произведения в кинотекст. Установлено, что при создании киноверсии романа (полисемиотической системы) востребованы приемы трансформации вербального текста, аналогичные приемам перевода в границах одной (вербальной) семиотической системы: компрессия, пермутация, проявляющаяся в форме перефразирования или перестановки, а также модуляция как адекватная замена и разъяснительный перевод. Показано, что средства выражения эмоций, избранные для интерсемиотического перевода, содержательно адекватны вербальным средствам, использованным в литературном произведении.

Ключевые слова: коммуникативное действие, визуализация, вербальный компонент коммуникации, невербальный компонент коммуникации, трансформация, кинотекст, эмоциональность, П. Зюскинд.

Цитирование. Несмачнова Е. В. Экспликация эмоций в тексте и кинотексте: интерсемиотический перевод романа П. Зюскинда «Парфюмер. История одного убийцы» // Вестник Волгоградского государственного университета. Серия 2, Языкознание. - 2017. - Т. 16, № 3. - С. 214-220. - DOI: https://doi.org/10.15688/ jvolsu2.2017.3.22

\section{1}

Стремительная визуализация культуры ставит новые задачи перед антропоцентрической лингвистикой, реализующей комплексный подход к изучению средств взаимодействия членов социума. Как подчеркивает В.А. Митягина, коммуникативная компетенция индивида стала экзистенциальной в постиндустриальном мире [Митягина, 2013, с. 9]. При этом роль вербальных средств в коммуникативном процессе изменяется, поскольку изобразительный ряд превращается из подчиненного знакового комплекса в равноправный, а в ряде дискурсов в ведущий коммуникативный инструментарий.

Кинофильм как многомерный и многоплановый объект исследования подвергается анализу во многих науках: эстетике, семиотике, литературоведении, лингвистике. По мнению Е.А. Колодиной, в этих областях научного знания выявляются те или иные характеристики кино как сложного образования, включающего в себя несколько систем функционирования бытия [Колодина, 2013, с. 327].

Кинематограф как знаковая система объединяет достижения цивилизации, духовный и художественный потенциал современного социума. Кино стало основой для всех аудиовизуальных СМИ, а стремительное развитие таких масштабных дискурсов, как рекламный, персональный, виртуальный в сторону фото- и видеопрезентаций объективно инициирует необходимость анализа причин и логики преобразования вербального текста с позиций интерсемиотического перевода. Это понятие введено Р. Якобсоном и трактуется как перевод текста из одной семиотической системы в другую, интерпретация вербальных знаков посредством невербальных знаковых систем [Якобсон, 1985]. Изучение интерсемиотического перевода в коммуникативном аспекте является новым вектором комплексного исследования вербальных и невербальных средств коммуникации. Понятие интерсемиотического перевода применимо и к процессу адаптации литературного произведения в произведение кинематографа, которую можно рассматривать как процесс перевода из текстовой системы в синтетическую.

Поскольку, как пишет М.Б. Ворошилова, кинематограф - это новый вид искусства, это рассказывание истории средствами изображения [Ворошилова, 2007, с. 106], перспективным представляется выявление сходства и различия планов содержания и выражения художественного произведения как первоисточника и его экранизации. Объектом исследования в данной статье стали речевые средства экспликации эмоций главного героя в книге и фильме.

2

Одним из произведений, весьма сложных для экранизации, является вышедший в 1985 г. роман известного немецкого писателя и киносценариста Патрика Зюскинда (Patrik Süskind) «Парфюмер. История одного убийцы» (Das Parfum. Die Geschichte eines Mörders). Этот роман уже более 30 лет занимает ведущие позиции в списке мировых бестселлеров, на 


\section{МАТЕРИАЛЫ И СООБЩЕНИЯ}

сегодняшний день он переведен на 46 языков и стал предметом лингвистического изучения. Например, в диссертационном исследовании М.В. Никитиной предпринят анализ особенностей поэтики романа, его жанровой специфики, заключающейся в сочетании пародии на «криминальный роман», «роман воспитания» и «роман о художнике» [Никитина, 2006]. Предметом изучения в работе Ю.А. Старостиной выступает концепт «запах»: показано, что метафора является основным языковым средством репрезентации этого индивидуально-авторского концепта [Старостина, 2010]. Кроме того, установлено, что индивидуальноавторский концепт «запах» коррелирует в романе с концептами «красота», «душа», «язык» как наиболее значимыми для реализации идеи романа, в результате корреляций концепта «запах» с концептами «душа» и «красота» обонятельные ощущения приобретают в тексте романа дополнительные индивидуально-авторские характеристики запаха как фактора, объединяющего живые и неживые существа, и запаха как способа выражения красоты [Старостина, 2010].

Эмоциональный фон является, таким образом, значимой составляющей произведения, но его экспликация еще не стала предметом специального лингвистического исследования. Эмоции, будучи неотъемлемой частью коммуникации, способны как объединять, так и разъединять ее участников. Как отмечает В.И. Шаховский, языковые личности, независимо от их культурных различий, переживают одни и те же базовые эмоции, что объединяет людей; эмоции делают людей разных культур более или менее похожими друг на друга, а также делают нас уникальными в силу индивидуального варьирования базовых и иных эмоций [Шаховский, 2008, с. 144]. Подобно любому компоненту коммуникации, они могут быть универсальными, культурно-специфичными и индивидуальными. Эмоции разнообразны по своей природе, содержанию и проявлению. Эмотивность, согласно В.И. Шаховскому, имманентно присуща языку, это его семантическое свойство выражать системой своих средств эмоциональность как факт психики человека, социальные и индивидуальные эмоции [Шаховский, 1987, с. 24]. Однако психологические исследования показали, что большую часть информации в процессе общения человек получает через невербальные средства коммуникации, следовательно, невербальное поведение является внешней формой существования и проявления эмоций. Смена эмоциональных состояний сопровождается изменением всей деятельности человека. Потому и возникает, по мнению Е.А. Зуевой, повышенное внимание ученых различных отраслей науки к невербальному поведению человека в процессе коммуникации как способу выражения его эмоционального состояния [Зуева, 2006, с. 148].

С целью установить возможности передачи содержания вербального текста в иных семиотических системах сопоставим текст романа и немецкоязычную версию одноименного фильма: Das Parfum. Die Geschichte eines Mörders (реж. Том Тыквер (Tom Tykwer), 2006).

Невербальное проявление эмоций в кинофильме становится ключевым, так как человек, переполненный эмоциями, не способен выражать их только вербально.

Главный герой романа Жан-Батист Гренуй - гений запахов, но в основе его гения не обоняние человека, а изощренный нюх животного. Единственным типом отношений Гренуя с природой и людьми является непреодолимое желание впитывать, забирать и сохранять запахи, поэтому целью для Жан-Батиста Гренуя становится создание единственного и неповторимого аромата, способного сводить с ума и подчинять себе толпы людей, а цена получения такого аромата - жизнь невинных девушек.

Жан-Батист Гренуй - сложный и загадочный герой, его восприятие окружающего мира далеко от обычного. Эмоциональный образ главного героя в книге и в кинокартине, несмотря на многие сходства, все же имеет немало отличий. В экранизации Гренуй показан как человек, почти лишенный эмоций, выражение его лица всегда одинаково, а речь кратка и монотонна. Весь его эмоциональный фон в фильме представлен запахами, которые он держит в голове. Жан-Батист не утруждается подбирать им слова, так как считает, что человеческий язык слишком скуден и не дает возможности передать все обонятельные ощущения, это подробно описано и в книге. Главный герой спосо- 
бен бурно выражать свои эмоции невербально. Примером может служить сцена прибытия Гренуя в место, лишенное человеческих запахов, именно поэтому приведшее его в неописуемый восторг:

Ein ungeheurer Jubel brach in ihm aus. Grenouille feierte seine Ankunft auf dem Berg der Einsamkeit. Er schrie vor Glück. Rucksack, Decke, Stock warf er von sich und trampelte mit den Füßen auf den Boden, warf die Arme in die Höhe, tanzte im Kreis, brüllte seinen eigenen Namen in alle vier Winde, ballte die Fäuste, schüttelte sie triumphierend gegen das ganze weite unter ihm liegende Land und gegen die sinkende Sonne, triumphierend, als hätte er sie persönlich vom Himmel verjagt. Er führte sich auf wie ein Wahnsinniger, bis tief in die Nacht hinein (Süskind, S. 147).

Гренуй испытывает целый ряд положительных эмоций, прежде всего ликование и счастье, которые выражены как вербальными (выкрикивание собственного имени), так и невербальными (топанье, жесты, танец) средствами. Однако данный фрагмент отсутствует в экранизации, которая предлагает иное толкование образа главного героя: в фильме Гренуй представлен неспособным на нормальное человеческое выражение эмоционального состояния.

Для установления приемов интерсемиотической трансформации обратимся к фрагментам текста произведения, которые представлены и в книге.

Часто кинотекст является результатом компрессии литературного первоисточника, например:

Er mied jetzt nicht mehr nur die Städte, er mied auch die Dörfer. Er war wie berauscht von der sich immer starker ausdünnenden, immer menschenferneren Luft. Er flüchtete weiter, immer sensibler reagierend auf den immer seltener werdenden Geruch des Menschlichen. So führte ihn seine Nase in immer abgelegenere Gegenden des Landes, entfernte ihn immer weiter von den Menschen und trieb ihn immer heftiger dem Magnetpol der größtmöglichen Einsamkeit entgegen (Süskind, S. 142).

Es gab zwei Wege nach Grasse: Die erste folgte den gewundenen Strassen durch die Dörfer, der zweite führte in gerader Linie über Hügel und Gebirge in die Provance. Die Wahl fiel ihm leicht. So führte ihn seine Nase immer weiter fort von den Menschen und trieb ihn immer heftiger dem Magnetpol der größtmöglichen Einsamkeit entgegen (56 min).

Этот текст, произнесенный от имени автора, сопровождает визуальный ряд; в описании эмоционального состояния героя переданы доминирующие чувства облегчения и ощущения свободы: находясь вдали от людей, Гренуй может вдыхать чистый и свежий воздух, что представляется ему высшим благом. Выделенное предложение максимально сохранено в кинотексте, но по сравнению с оригиналом является более емким, поскольку наличествует видеоряд.

При трансформации текста романа в кинотекст часто используется прием пермутации, например:

Da war nur Ruhe, wenn man so sagen kann, gerüchliche Ruhe. Ringsum herrschte nur der wie ein leises Rauschen wehende, homogene Duft der toten Steine.

Nahe der Wasserstelle entdeckte er einen natürlichen Stollen. Es überfiel ihn beinahe ein Gefühl von heiliger Scheu, als er ihn in Besitz nahm. Er fühlte sich himmlisch wohl. Noch nie im Leben hatte er sich so sicher gefühlt. Er begann still zu weinen. Er wußte nicht, wem er danken sollte für so viel Glück. Er badete in seiner eigenen, durch nichts mehr abgelenkten Existenz und fand das herrlich. So ging es sieben ganze Jahre lang (Süskind, S. 148-149).

Grenouille brauchte Zeit, bis er merkte, dass er einen Ort gefunden hatte, wo Gerüche so gut wir abwesend waren. Ringsum herrschte nichts außerdem stillen Duft von totem Stein. Der Ort hatte etwas Heiliges an sich. Nicht langer abgelenkt von jedwedem außeren, konnte er endlich ungestört in seiner eigenen Existenz baden. Und fand es herrlich. Mit der Zeit verflüchtigten sich Grenouilles Pläne und Obsession, und vielleicht hatte er hier den Rest seines Lebens verbringen können (57-58 min).

В кинотексте сохранен общий посыл автора и экспликация эмоционального состояния героя: Гренуй стремится уйти как можно дальше от людей, чтобы добиться максимально возможного одиночества, которое является для него наивысшим блаженством. В данном фрагменте наблюдается дословный перевод текста оригинала в кинотекст лишь в пределах одного предложения: Und fand es herrlich. 


\section{МАТЕРИАЛЫ И СООБЩЕНИЯ}

Остальные фрагменты (выделены полужирным) представляют собой пермутацию в форме перефразирования и перестановок.

Весьма значимым для наблюдений над интерсемиотическим переводом является описание сна Гренуя в романе и фильме. В книге говорится о том, что во сне главный герой видит болото и туман, который, обволакивая Гренуя, пытается его задушить, туман представлен как запах, запах самого Гренуя, удушающий по своей природе и неопределенный для его обладателя. Герой с ужасом просыпается и начинает себя тщательно обнюхивать, но не чувствует никакого запаха своего тела. Он до последнего не верит, что не имеет собственного запаха (Süskind, S. 162-167). В фильме показано, что Гренуй во сне видит рыжеволосую девушку, чей запах он все еще хранит в своей памяти. Во сне он подходит к ней, вдыхая ее аромат, как это и было когдато на самом деле, но, когда девушка оборачивается, она не видит Гренуя, будто он призрак или его вовсе нет. Гренуй просыпается в ужасе; как и в книге, он начинает себя обнюхивать и понимает, что у него нет собственного запаха (59-60 min.).

Данная трансформация вполне оправдана, так как изображение сна главного героя, описанного в книге, его образность и метафоричность сложно передать визуальными средствами, тогда как зрительный образ прекрасной девушки, не увидевшей Гренуя, ярок и эффектен. Здесь при интерсемиотическом переводе актуализирован прием модуляции как адекватной замены. Краткое закадровое пояснение автора (разъяснительный перевод) дает зрителю возможность правильно воспринять и осознать сновидение героя:

Grenouille begriff zum ersten Mal, dass er selbst keinen Geruch besass. Er begriff, dass er sein Leben lang für alle ein Niemand gewesen war. Was er jetzt empfand, war die Angst, tatsächlich nicht vorhanden zu sein, gerade so, als existierte er nicht.

В данном фрагменте показано осознание Гренуем того, что он не имеет собственного запаха, и его чувства, связанные с этим открытием. Доминантой эмоционального состояния главного героя становится страх, который является для Гренуя самой сложной эмоцией, так как вызван ощущением собствен- ного небытия. Кинотекстовые средства, избранные для интерсемиотического перевода, представляются адекватными оригинальному произведению.

\section{4}

Проведя подробный анализ фрагментов романа и сравнив их с закадровым текстом фильма, мы установили, что в кинотексте доминируют приемы пермутации, компрессии и модуляции, являющиеся, как и в межъязыковом переводе, залогом успешного интерсемиотического перевода художественного произведения в кинотекст. Исследование экспликации эмоций средствами разных семиотических систем представляется продуктивным способом изучения коммуникативного поведения человека, детерминированности интеракционных процессов в разных социальных контекстах.

\section{СПИСОК ЛИТЕРАТУРЫ}

Ворошилова, М. Б. Креолизованный текст: кинотекст / М. Б. Ворошилова // Политическая лингвистика. - 2007. - Вып. (2) 22. - С. 106-110.

Зуева, Е. А. Эмоции как объект лингвистических исследований / Е. А. Зуева // Иностранные языки в профессиональном образовании: лингвометодический контекст : материалы межвуз. науч.-практ. конф. (Белгород, 17-18 мая 2006 г.). - Белгород : Белгор. ун-т потреб. кооперации, 2006. -С. 148-154.

Колодина, Е. А. Статус кинодиалога в ряду соположенных понятий: кинодиалог, кинотекст, кинодискурс / Е. А. Колодина // Вестник Нижегородского университета им. Н.И. Лобачевского. - 2013. № 2(1). - C. 327-333.

Митягина, В. А. Коммуникация и перевод в эпоху глобального поликультурного информационного пространства / В. А. Митягина // Подготовка переводчика: коммуникативные и дидактические аспекты : коллектив. моногр. / авт. колл.: В. А. Митягина и др. ; под общ. ред. В. А. Митягиной. - М. : ФЛИНТА : Наука, 2013. - С. 9-35.

Никитина, М. В. Роман «Парфюмер. История одного убийцы» в контексте творчества Патрика Зюскинда : дис. ... канд. филол. наук / Никитина Мария Валентиновна. - Тамбов, 2006. - 170 с. - Электрон. текстовые дан. - Режим доступа: http://www.lib.uaru.net/diss/cont/175636.html. - Загл. с экрана.

Старостина, Ю. А. Метафора как средство языковой реализации концепта «запах»: на матери- 
але романа Патрика Зюскинда «Парфюмер. История одного убийцы» : дис. ... канд. филол. наук / Старостина Юлия Александровна. - Волгоград, 2010. - 173 с. - Электрон. текстовые дан. - Режим доступа: http://www.dslib.net/jazyko-znanie/metaforakak-sredstvo-jazykovoj-realizacii-koncepta-zapah-namateriale-romana.html. - Загл. с экрана.

Шаховский, В. И. Категоризация эмоций в лексико-семантической системе языка / В. И. Шаховский. - Воронеж : Изд-во ВГУ, 1987. - 190 с.

Шаховский, В. И. Лингвистическая теория эмоций / В. И. Шаховский. - М. : Гнозис, 2008. $416 \mathrm{c}$.

Якобсон, Р. О. О лингвистических аспектах перевода / Р. О. Якобсон // Избранные работы. - М. : Прогресс, 1985. - С. 16-24.

\section{ИСТОЧНИКИ}

Das Parfum. Die Geschichte eines Mörders. 2006. - Electronic text data. - Mode of access: https:/ /kat.cr/das-parfum-die-geschichte-eines-mrders-2006t740524.html. - Title from screen.

Süskind - Süskind, P. Das Parfum. Die Geschichte eines Mörders / P. Süskind. - Zürich : Diogenes Verlag AG, 1985. - 306 S.

\section{REFERENCES}

Voroshilova M.B. Kreolizovannyy tekst: kinotekst [Creolized Text: Film Text]. Politicheskaya lingvistika [Political Linguistics Journal], 2007, iss. (2) 22, pp. 106-110.

Zueva E.A. Emotsii kak obyekt lingvisticheskikh issledovaniy [Emotions as an Object of Linguistic Research]. Inostrannye yazyki v professionalnom obrazovanii: lingvometodicheskiy kontekst: materialy mezhvuz. nauch.-prakt. konf. (Belgorod, 17-18 maya 2006 g.) [Foreign Languages in Vocational Education: Linguomethodical Context: Materials of Interuniversity Scientific-Practical Conference (Belgorod, May 17-18, 2006)]. Belgorod, Belgor. un-t potreb. kooperatsii, 2006, pp. 148-154.

Kolodina E.A. Status kinodialoga v ryadu sopolozhennykh ponyatiy: kinodialog, kinotekst, kinodiskurs [Status of the Film Dialog Among Juxtaposed Concepts: Film Dialog, Film Text, Film Discourse]. Vestnik Nizhegorodskogo universiteta im. N.I. Lobachevskogo [Vestnik of Lobachevsky
University of Nizhni Novgorod], 2013, no. 2 (1), pp. 327-333.

Mityagina V.A. Kommunikatsiya i perevod v epokhu globalnogo polikulturnogo informatsionnogo prostranstva [Communication and Translation in the Multicultural Era of Global Information Space]. Mityagina V.A., ed. Podgotovka perevodchika: kommunikativnye i didakticheskie aspekty: kollektiv. monogr. [Training of Translators: Communicative and Didactic Aspects: Collective Monograph]. Moscow, Flinta: Nauka Publ., 2013, pp. 9-35.

Nikitina M.V. Roman «Parfyumer. Istoriya odnogo ubiytsy» v kontekste tvorchestva Patrika Zyuskinda: dis. ... kand. filol. nauk [The Novel Perfume: The Story of a Murderer in the Context of Patrick Suskind's Art. Cand. philol. sci. diss.]. Tambov, 2006. 170 p. URL: http://www.lib.ua-ru.net/diss/cont/ 175636.html. (accessed September 28, 2016).

Starostina Yu.A. Metafora kak sredstvo yazykovoy realizatsii kontsepta «zapakh»na materiale romana Patrika Zyuskinda «Parfyumer: Istoriya odnogo ubiytsy»: dis. ... kand. filol. nauk [The Metaphor as a Language Means of Implementation of the Concept "Smell" (Based on the Novel by Patrick Suskind Perfume: The Story of a Murderer. Cand. philol. sci. diss.]. Volgograd, 2010. 173 p. URL: http://www.dslib.net/jazyko-znanie/ metafora-kak-sredstvo-jazykovoj-realizacii-konceptazapah-na-materiale-romana.html. (accessed September 28, 2016).

Shakhovskiy V.I. Kategorizatsiya emotsiy $v$ leksiko-semanticheskoy sisteme yazyka [Categorization of Emotions in the Lexical-Semantic System of Language]. Voronezh, Izd-vo VGU, 1987. 190 p.

Shakhovskiy V.I. Lingvisticheskaya teoriya emotsiy [Linguistic Theory of Emotions]. Moscow, Gnozis Publ., 2008. 416 p.

Yakobson R.O. O lingvisticheskikh aspektakh perevoda [On Linguistic Aspects of Translation]. Izbrannyye raboty [Selected Works]. Moscow, Progress Publ., 1985, pp. 16-24.

\section{SOURCES}

Das Parfum. Die Geschichte eines Mörders, 2006. URL: https://kat.cr/das-parfum-die-geschichteeines-mrders-2006-t740524.html.

Süskind P. Das Parfum. Die Geschichte eines Mörders. Zürich, Diogenes Verlag AG, 1985. 306 p. 


\section{МАТЕРИАЛЫ И СООБЩЕНИЯ}

\section{Information about the Author}

Ekaterina V. Nesmachnova, Postgraduate Student, Department of Translation Theory and Practice, Volgograd State University, Prosp. Universitetsky, 100, 400062 Volgograd, Russian Federation, nesmachnova@volsu.ru, http://orcid.org/0000-0002-5316-9040

\section{Сведения об авторе}

Екатерина Владимировна Несмачнова, аспирант кафедры теории и практики перевода, Волгоградский государственный университет, просп. Университетский, 100, 400062 г. Волгоград, Российская Федерация, nesmachnova@volsu.ru, http://orcid.org/0000-0002-5316-9040 